\title{
THE POTENTIAL BENEFIT OF INTRACARPAL PRESSURE MEASUREMENT IN ENDOSCOPIC CARPAL TUNNEL SYNDROME SURGERY - AN ANALYSIS OF EMG FINDINGS AND PRESSURE VALUES
}

\author{
Martin Kanta ${ }^{1}$, Edvard Ehler ${ }^{3}$, Jan Kremláček ${ }^{2}$, Svatopluk Řehák ${ }^{1}$, David Laštovička ${ }^{1}$, Jaroslav Adamkov ${ }^{1}$, \\ Jiřina Habalová ${ }^{\text {, Michael Bartošs }}$
}

Charles University in Prague, Faculty of Medicine and University Hospital Hradec Králové, Czech Republic: Department of Neurosurgery ${ }^{1}$, Department of Pathological Physiology²; Regional Hospital, Pardubice, Czech Republic: Department of Neurology

\begin{abstract}
Summary: Endoscopic carpal tunnel syndrome surgery is a modern minimally invasive method of carpal tunnel decompression. However, the method does also have its critics, who emphasize that there is an increased rate of complications in comparison to open procedures. To further improve and optimize results of endoscopic surgery we used an intracarpal pressure sensor to verify the effect of carpal tunnel decompression. The endoscopic single portal approach was used in all cases. Median nerve conduction studies were performed prior to and 3 months after surgery. Two groups, those with pressure studies and those without, were then compared according to several EMG parameters such as: median nerve distal motor latency, amplitude of motor response, sensory nerve conduction velocity to the index finger, and amplitude of sensory nerve action potential. In both groups, we observed similarly significant improvements in all conduction parameters, except the amplitude of motor response, which did not change in either group, i.e. no difference in postoperative EMG between the two groups was observed. Despite this fact, intracarpal pressure measurement is still useful in localising the point in which the median nerve is compressed and provides valuable functional information on the level decompression achieved.
\end{abstract}

Key words: Endoscopic carpal tunnel surgery; Intracarpal pressure measurements; Conduction studies

\section{Introduction}

Several methods of carpal tunnel syndrome (CTS) surgery have been described. The open approach is regarded as the gold standard, however there are also many critics of this technique. Due to the fact that results of open surgery are often quite disappointing - about $60 \%$ of patients have scar pain or so called pillar pain in the hypothenar and thenar eminences following surgery, we have therefore, turned our interests to less invasive techniques. In the past 12 years, we have accumulated vast experience in CTS surgery, which is a very frequent procedure in our department. Other than the classic open approach, we have obtained experience in the so called „twin incision technique“ (1) „flexor carpi radialis approach“ (20) and the uniportal (single portal) endoscopic approach (9). Endoscopy is our favoured technique (system Wolf). In most cases of mild or moderate EMG findings, using the endoscopic technique we were able to achieve superior patient satisfaction rates.

Intracarpal pressure (ICP) measurement has a long history. The accepted normal ICP range in healthy indivi- duals is between 3-6 mmHg in the neutral wrist position and up to 20-60 mmHg during extension (21). The positive results of certain groups, especially studies done by Japanese authors have led us to further improve our results. In our study, a Codman sensor, typically used for the measurement of intracranial pressure was used to measure intracarpal pressure. The main reason for ICP measurement was to evaluate the relationship between peroperative intracarpal pressure, the level of decompression and pre/postoperative EMG findings. In addition, the effect of different hand positions and anatomical location on ICP was assessed.

\section{Material and Methods}

Surgery: All procedures were performed by two neurosurgeons from 2005-2006 under local anesthesia with 1\% trimecain. The incision was made between the palmaris longus and flexor carpi ulnaris tendons $-1 \mathrm{~cm}$ in length. With the use of a dissector, subcutaneous tissue was dissected and then fibres of the antebrachial fascia were bluntly se- 
parated in order to reach the subfascial space. The antebrachial fascia was then undermined, firstly proximally and then distally through the carpal tunnel to the palmar space, so that the pressure sensor could be inserted. Pressure readings were recorded in the distal antebrachial space, proximal/ medial/distal carpal tunnel and the palmar space distal to the carpal tunnel. Pressure measurements were also recorded in different hand positions (neutral, maximum passive flexion, maximum passive extension and passive hand grip). This method of measurement was adopted from studies by Gelbermann (4), Okutsu (12, 13), Hashizume (6), but using a different type of sensor. The undermined antebrachial fascia was then transsected using scissors to release this part of the median nerve. The next step was the insertion of the endoscopic cannula with 30 degree optics into the carpal tunnel. The carpal ligament was then transsected using the endoscopic blade. ICP after transsection was recorded in the same areas and positions as described above. ICP was measured in group I, group II was the control.

The EMG measurements were performed prior to and 3 months after surgery. The following parameters were eva-

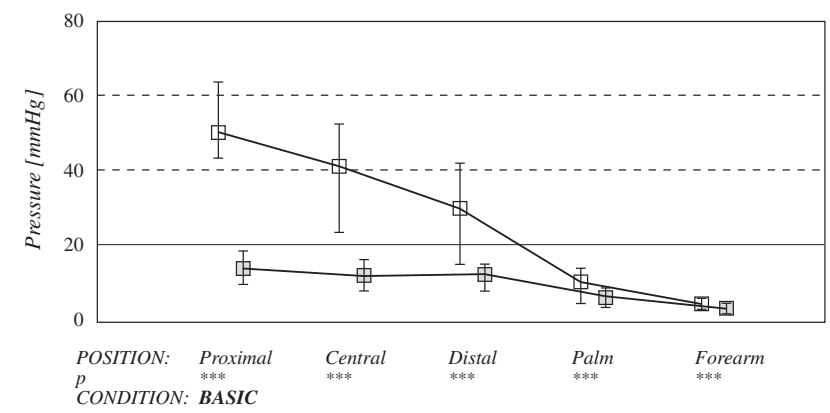

Fig. 1: Pressure values before (open squares) and after trans-section of ligament (gray filled squares) for neutral condition in the five measuring places. The values are represented as the mean as the square and the upper and lower quartiles as the whiskers.

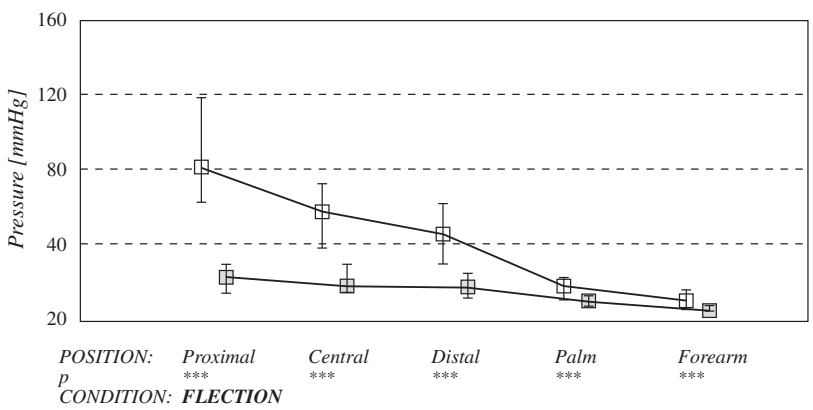

Fig. 2: Pressure values before (open squares) and after trans-section of ligament (grey filled squares) for flexion condition in the five measuring places. The values are represented as the mean as the square and the upper and lower quartiles as the whiskers. luated: DML (distal motor latency), ACMAP (amplitude of motor response), SCV (sensory nerve conduction velocity to index finger), and ASNAP (amplitude of sensory nerve action potential).

Patient characteristics: Thirty-one patients in group I (ICP measured) and 33 patients in group II (control group) were operated on for CTS. Two patients in group I and 1 patient in group II did not have EMG follow-ups. These patients were excluded from all statistical analyses.

Characteristics of Group I: 29 subjects (3 males) aged 27 to 78 with a median age of 57 years. Lower quartile 53 and upper 59 years.

Characteristics of the Group II: 32 subjects ( 5 males) aged 24 to 83 with a median age of 55 years. Lower quartile 50 and upper 64 years.

The relationship between pressure recordings and EMG findings was analysed using the Spearman rank order correlation test. EMG findings of the two groups were then compared using the Mann-Whitney U-test for independent measurements. Due to the non-normal distribution of pressure values we used the Wilcoxon paired test to compare

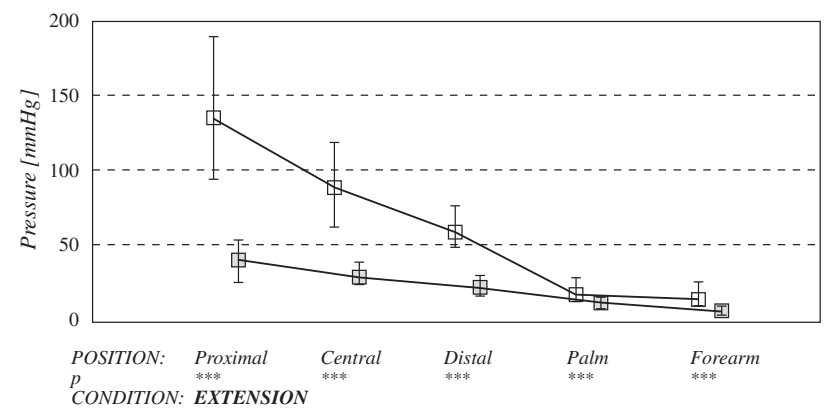

Fig. 3: Pressure values before (open squares) and after trans-section of ligament (grey filled squares) for extension condition in the five measuring places. The values are represented as the mean as the square and the upper and lower quartiles as the whiskers.

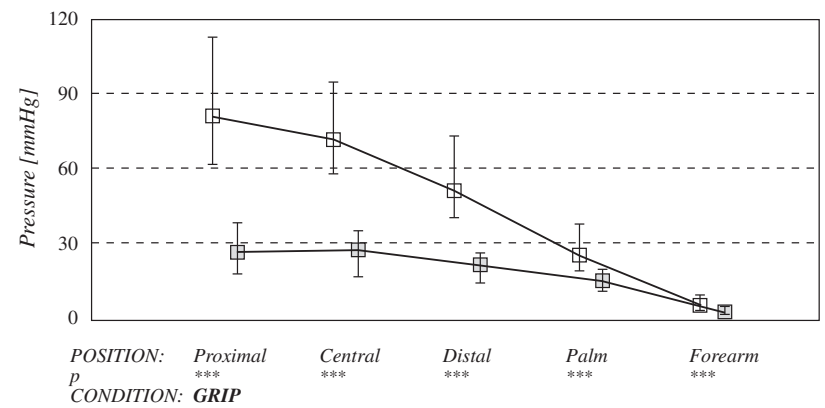

Fig. 4: Pressure values before (open squares) and after trans-section of ligament (grey filled squares) for grip condition in the five measuring places. The values are represented as the mean as the square and the upper and lower quartiles as the whiskers. 
values before and after surgery. The level of statistical significance was determined at 0.05 in all cases. For statistical evaluation we used Statistica (ver. 6.1) software.

\section{Results}

The results of the Wilcoxon paired test, used to assess pressure levels before and after surgery, showed a significant decrease in pressure after ligament transsection, in all areas and positions (see Figs. 1-4 and Tab. 1).

The results of the Spearman correlation test, did not prove a significant correlation between pressure measurements and EMG findings ( 3 of 320 evaluations - 4 EMG parameters and 20 pressure measurements before and after the surgery. The calculated correlations did not overcome the Spearman $r=0.5$ and were not systematic in a pathophysiological sense.

The results of the Mann-Whitney U test of EMG findings, before and after surgery, showed a significant improvement in all parameters except ACMAP.

When EMG findings of groups I and II before and after surgery were compared, there was only an insignificant difference in the rate of improvement (Tabs. 2-5).

\section{Discussion}

There is no doubt about the high success rate of the classic midpalmar approach in CTS surgery. However, ac-

Tab. 1: Pressure values before and after treatment in the group I. The statistical comparison based on Wilcoxon Matched Pairs Test proved highly significant decrease of the pressure after the ligament transsection in the all recorded locations and hand positions - see the most right column.

\begin{tabular}{|c|c|c|c|c|c|c|c|c|c|c|c|c|c|}
\hline & & \multirow[b]{2}{*}{$\mathrm{n}$} & \multicolumn{5}{|c|}{ Pressure before therapy [mmHg] } & \multicolumn{5}{|c|}{ Pressure after therapy [mmHg] } & \multirow[b]{2}{*}{$\mathrm{p}$} \\
\hline & & & median & $25 \%$ & $75 \%$ & $\min$ & $\max$ & median & $25 \%$ & $75 \%$ & $\min$ & $\max$ & \\
\hline \multirow[t]{5}{*}{ Basic } & Proximal & 31 & 50.0 & 43.0 & 63.0 & 16.0 & 76.0 & 14.0 & 9.5 & 18.5 & 5.0 & 32.0 & $1.2 \mathrm{E}-06$ \\
\hline & Central & 31 & 41.0 & 23.5 & 52.5 & 10.0 & 74.0 & 12.0 & 8.0 & 16.0 & 4.0 & 30.0 & $1.2 \mathrm{E}-06$ \\
\hline & Distal & 31 & 30.0 & 15.0 & 42.0 & 6.0 & 69.0 & 12.0 & 8.0 & 15.0 & 3.0 & 30.0 & $6.7 \mathrm{E}-06$ \\
\hline & Palm & 31 & 10.0 & 4.5 & 14.0 & 1.0 & 30.0 & 6.0 & 3.5 & 8.0 & 1.0 & 16.0 & 5.2E-04 \\
\hline & Forearm & 31 & 4.0 & 2.5 & 5.0 & 0.0 & 18.0 & 3.0 & 2.0 & 4.0 & 0.0 & 7.0 & 5.8E-04 \\
\hline \multirow[t]{5}{*}{ Flection } & Proximal & 31 & 82.0 & 64.0 & 119.5 & 32.0 & 280.0 & 23.0 & 14.0 & 30.0 & 7.0 & 55.0 & $1.2 \mathrm{E}-06$ \\
\hline & Central & 31 & 58.0 & 38.5 & 72.5 & 24.0 & 130.0 & 18.0 & 14.0 & 30.0 & 8.0 & 91.0 & $1.2 \mathrm{E}-06$ \\
\hline & Distal & 31 & 45.0 & 29.5 & 62.0 & 9.0 & 128.0 & 17.0 & 11.5 & 25.0 & 3.0 & 36.0 & $1.3 \mathrm{E}-06$ \\
\hline & Palm & 31 & 18.0 & 10.0 & 20.5 & 2.0 & 101.0 & 9.0 & 6.0 & 12.0 & 3.0 & 22.0 & $9.3 \mathrm{E}-06$ \\
\hline & Forearm & 31 & 10.0 & 6.0 & 15.5 & 3.0 & 30.0 & 4.0 & 4.0 & 7.5 & 1.0 & 15.0 & 7.3E-06 \\
\hline \multirow[t]{5}{*}{ Extension } & \begin{tabular}{|l|} 
Proximal \\
\end{tabular} & 31 & 135.0 & 94.5 & 190.0 & 26.0 & 260.0 & 40.0 & 25.5 & 54.0 & 12.0 & 120.0 & $1.2 \mathrm{E}-06$ \\
\hline & Central & 31 & 89.0 & 62.0 & 120.0 & 20.0 & 230.0 & 29.0 & 24.5 & 38.5 & 14.0 & 80.0 & 1.9E-06 \\
\hline & Distal & 31 & 60.0 & 49.0 & 77.0 & 18.0 & 160.0 & 23.0 & 17.0 & 30.0 & 9.0 & 44.0 & $1.2 \mathrm{E}-06$ \\
\hline & Palm & 31 & 18.0 & 11.5 & 28.5 & 6.0 & 45.0 & 11.0 & 6.5 & 17.5 & 2.0 & 40.0 & $1.2 \mathrm{E}-05$ \\
\hline & Forearm & 31 & 13.0 & 9.0 & 26.5 & 5.0 & 41.0 & 7.0 & 4.5 & 9.5 & 3.0 & 17.0 & 1.4E-06 \\
\hline \multirow[t]{5}{*}{ Grip } & Proximal & 31 & 82.0 & 62.0 & 113.0 & 38.0 & 226.0 & 27.0 & 19.5 & 39.0 & 10.0 & 86.0 & $1.2 \mathrm{E}-06$ \\
\hline & Central & 31 & 72.0 & 59.0 & 95.0 & 32.0 & 140.0 & 28.0 & 18.0 & 36.0 & 11.0 & 50.0 & $1.7 \mathrm{E}-06$ \\
\hline & Distal & 31 & 52.0 & 41.0 & 73.5 & 20.0 & 200.0 & 22.0 & 15.5 & 28.0 & 10.0 & 41.0 & $1.3 \mathrm{E}-06$ \\
\hline & Palm & 31 & 26.0 & 20.5 & 38.5 & 7.0 & 120.0 & 16.0 & 12.0 & 20.5 & 4.0 & 48.0 & $6.3 \mathrm{E}-06$ \\
\hline & Forearm & 31 & 6.0 & 4.0 & 10.0 & 1.0 & 47.0 & 3.0 & 2.0 & 5.0 & 1.0 & 13.0 & $8.3 \mathrm{E}-06$ \\
\hline
\end{tabular}

Tab. 2: Distal motor latency descriptive parameters before and after treatment in the group1 consisting of patients with measured pressure in upper part of the table and the control group 2 in the bottom part. Nonparametric paired comparison within both groups, listed in the most right column, shows significant decrease of the DML after the treatment. Between groups comparison in the bottom row did not show any significant differences neither before nor after treatment.

\begin{tabular}{|c|c|c|c|c|c|c|c|c|}
\hline \multicolumn{9}{|l|}{ DML [ms] } \\
\hline & & befor & ment & after & nent & & & p value* \\
\hline \multirow{3}{*}{$\begin{array}{l}\text { Group } 1 \\
\mathrm{n}=29 \text { pairs }\end{array}$} & median & & & & & & & \multirow{3}{*}{ 2.6E-06 } \\
\hline & $25-75 \%$ percentile & 5.5 & 7.2 & 4.4 & 5.4 & 0.5 & 1.9 & \\
\hline & $\min -\max$ & 4.2 & 14.6 & 3.5 & 6.5 & 0.0 & 9.4 & \\
\hline \multirow{4}{*}{$\begin{array}{l}\text { Group } 2 \\
\mathrm{n}=32 \text { pairs }\end{array}$} & median & & & & & & & \multirow{3}{*}{$1.7 \mathrm{E}-06$} \\
\hline & $25-75 \%$ percentile & 5.0 & 7.0 & 4.3 & 5.0 & 0.4 & 2.2 & \\
\hline & $\min -\max$ & 3.3 & 8.4 & 3.3 & 6.0 & 0.0 & 4.0 & \\
\hline & p value ** & \multicolumn{2}{|c|}{$2.9 \mathrm{E}-01$} & & & \multicolumn{2}{|c|}{$6.5 \mathrm{E}-01$} & \\
\hline
\end{tabular}

*Wilcoxon Matched Pairs Test; **Mann-Whitney U test 
Tab. 3: Amplitude-Compound Motor Action Potential parameters are listed in the same arrangement as in Table 1. The statistical comparisons did not exhibit between groups or treatment effect.

\begin{tabular}{|c|c|c|c|c|c|c|c|c|}
\hline \multicolumn{9}{|c|}{ A-CMAP [mV] } \\
\hline & & befor & ment & after & nent & & & p value* \\
\hline \multirow{3}{*}{$\begin{array}{l}\text { Group } 1 \\
\mathrm{n}=29 \text { pairs }\end{array}$} & median & & & & & & & \multirow{3}{*}{ 2.0E-01 } \\
\hline & $25-75 \%$ percentile & 2.6 & 7.6 & 3.5 & 8.4 & -1.6 & 0.4 & \\
\hline & $\min -\max$ & 0.2 & 13.5 & 0.1 & 13.5 & -5.0 & 3.9 & \\
\hline \multirow{4}{*}{$\begin{array}{l}\text { Group } 2 \\
\mathrm{n}=32 \text { pairs }\end{array}$} & median & \multicolumn{2}{|c|}{6.1} & \multicolumn{2}{|c|}{6.3} & \multicolumn{2}{|c|}{-0.4} & \multirow{3}{*}{ 8.0E-02 } \\
\hline & $25-75 \%$ percentile & 4.5 & 8.5 & 4.7 & 9.6 & -1.2 & 0.2 & \\
\hline & $\min -\max$ & 0.6 & 10.2 & 0.7 & 11.9 & -6.4 & 1.9 & \\
\hline & $\mathrm{p}$ value** & \multicolumn{2}{|c|}{$3.1 \mathrm{E}-01$} & \multicolumn{2}{|c|}{$2.3 \mathrm{E}-01$} & \multicolumn{2}{|c|}{$9.4 \mathrm{E}-01$} & \\
\hline
\end{tabular}

*Wilcoxon Matched Pairs Test; **Mann-Whitney U test

Tab. 4: Amplitude sensitive nerve action potential parameters before and after treatment in the group 1 consisting of patients with measured pressure in upper part of the table and the control group 2 in the bottom part. Nonparametric paired comparison within both groups, listed in the most right column, shows significant decrease of the A-SNAP after the treatment. Between groups comparison in the bottom row did not showed any significant differences neither before nor after the treatment.

\begin{tabular}{|c|c|c|c|c|c|c|c|c|}
\hline \multicolumn{9}{|c|}{ A-SNAP [mV] } \\
\hline & & befor & ment & after & nent & & & p value* \\
\hline \multirow{3}{*}{$\begin{array}{l}\text { Group } 1 \\
\mathrm{n}=29 \text { pairs }\end{array}$} & median & & & & & & & \multirow{3}{*}{ 2.6E-04 } \\
\hline & $25-75 \%$ percentile & 0.0 & 4.5 & 2.5 & 10.0 & -5.3 & -0.4 & \\
\hline & $\min -\max$ & 0.0 & 22.2 & 0.0 & 27.7 & -14.8 & 15.0 & \\
\hline \multirow{4}{*}{$\begin{array}{l}\text { Group } 2 \\
\mathrm{n}=32 \text { pairs }\end{array}$} & median & & & & & & & \multirow{3}{*}{$8.7 \mathrm{E}-06$} \\
\hline & $25-75 \%$ percentile & 0.0 & 5.1 & 3.2 & 9.5 & -4.5 & -1.0 & \\
\hline & $\min -\max$ & 0.0 & 9.9 & 0.0 & 14.5 & -11.5 & 2.9 & \\
\hline & p value** & \multicolumn{2}{|c|}{$9.6 \mathrm{E}-01$} & \multicolumn{2}{|c|}{$7.9 \mathrm{E}-01$} & \multicolumn{2}{|c|}{$7.0 \mathrm{E}-01$} & \\
\hline
\end{tabular}

*Wilcoxon Matched Pairs Test; **Mann-Whitney U test

Tab. 5: Sensory nerve conduction velocity parameters before and after treatment in the group 1 consisting of patients with measured pressure in upper part of the table and the control group 2 in the bottom part. Nonparametric paired comparison within both groups, listed in the most right column, shows significant decrease of the A-SNAP after the treatment. Between groups comparison in the bottom row did not showed any significant differences neither before nor after the treatment.

\begin{tabular}{|c|c|c|c|c|c|c|c|c|}
\hline \multicolumn{9}{|l|}{$\mathrm{SCV}[\mathrm{m} / \mathrm{s}]$} \\
\hline & & befor & tment & after & ment & & & $p$ valuex \\
\hline \multirow{3}{*}{$\begin{array}{l}\text { Group } 1 \\
\mathrm{n}=29 \text { pairs }\end{array}$} & median & & & & & & & \multirow{3}{*}{ 7.4E-05 } \\
\hline & $25-75 \%$ percentile & 0.0 & 38.0 & 32.2 & 45.5 & -30.6 & -2.0 & \\
\hline & $\min -\max$ & 0.0 & 45.0 & 0.0 & 54.4 & -54.4 & 36.4 & \\
\hline \multirow{4}{*}{$\begin{array}{l}\text { Group } 2 \\
\mathrm{n}=32 \text { pairs }\end{array}$} & median & \multicolumn{2}{|c|}{31.0} & \multicolumn{2}{|c|}{41.8} & \multicolumn{2}{|c|}{-9.8} & \multirow{3}{*}{$3.3 \mathrm{E}-06$} \\
\hline & $25-75 \%$ percentile & 0.0 & 40.6 & 36.9 & 48.7 & -20.2 & -3.0 & \\
\hline & $\min -\max$ & 0.0 & 54.7 & 0.0 & 57.2 & -41.5 & 3.1 & \\
\hline & $\mathrm{p}$ value $* *$ & \multicolumn{2}{|c|}{$2.7 \mathrm{E}-01$} & \multicolumn{2}{|c|}{$2.2 \mathrm{E}-01$} & \multicolumn{2}{|c|}{$7.7 \mathrm{E}-01$} & \\
\hline
\end{tabular}

*Wilcoxon Matched Pairs Test; **Mann-Whitney U test

cording to literature it also has a high percentage of postoperative sequelae such as pillar and scar pain. In our department, 4 different techniques are used. The classic midpalmar incision, the twin incision technique, the flexor carpi radialis approach and the uniportal endoscopic technique. Based on 12 years of experience we prefer the endoscopic approach. Almost all of our patients with mild or moderate CTS were operated on using the endoscopic technique. We have also used the method with success in some patients presenting with very severe clinical and/or EMG findings. In cases of thenar atrophy we most often use the classic midpalmar approach. Patients who depend on walking aids can profit from minimally invasive techniques due to less frequent scar and pillar pain.

In general we don't prefer endoscopic approach in cases after distal forearm, wrist and hand fractures, in patients with different hand anatomical anomalies, in cases of reoperations and after hand burns. 
According to certain authors $(2,16)$, endoscopic techniques have a higher incidence of recurrence and complications. Other literary sources do not suggest this $(3,8)$. A metaanalysis of randomized controlled trials (17) shows a reduction in scar tenderness and increase in grip and pinch strength at 12 week follow up in endoscopic group but also increases susceptibility to reversible nerve injury that is three times as likely to occur with endoscopic carpal tunnel release than with open carpal tunnel release. In our own experience based on a series of 500 cases, we reoperated in only one event for a motor branch lesion and patient's satisfaction has been approximately 93-94\%. Japanese authors $(5,12)$ have claimed to have a very high percentage of perfect results (99-100\%) when endoscopy is combined with intracarpal pressure measurement.

The types devices used for ICP measurement vary (4, $12,15)$. In this study we used a Codman sensor, frequently used in our department for intracranial pressure measurement. This sensor was tolerated very well without any difficulties.

The area in which the highest values were measured, irrespective of hand position, was the proximal carpal tunnel (Figs. 1-4). Based on hand position, the highest values were recorded during maximal extension, except in the palm where the highest pressure values were recorded during passive grip (Fig. 5). These results are in accordance with other authors $(4,6,7)$.

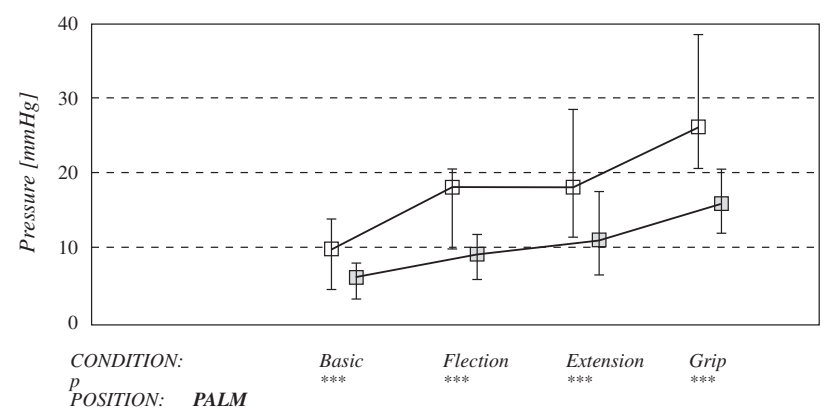

Fig. 5: Pressure values before (open squares) and after trans-section of ligament (grey filled squares) for palm position in 5 condition. The values are represented as the mean as the square and the upper and lower quartiles as the whiskers.

We did not document any relationship between the severity of EMG parameters changes and the level of intracarpal pressure. Some authors are of the same opinion (4, 6). It seems ICP pressure levels and EMG findings are independent of each other in patients with mild or moderate CTS. After CTS decompression there was a statistically significant improvement in all EMG parameters, except ACMAP, in both groups. However, the EMG improvement in the measured group was no better than the control group. These results are similar to those described in literature (18).
Median nerve conduction studies are necessary before performing CTS surgery. The most sensitive EMG parameter is decreased SCV, followed by prolonged DML and a decrease in A-SNAP. In mild and moderate CTS there is no change in A-CMAP, because there is no axonal lesion of median nerve motor fibres. The most common pathophysiological mechanism of CTS is the demyelination of nerve fibres due to median nerve entrapment. Recently, changes in nerve excitability associated with an activity dependent conduction block have been discovered $(14,19)$. These mechanisms could explain the immediate improvement of symptoms and relatively quick changes in conduction parameters following surgery (11). We should keep in mind that there are still some patients with clear symptoms of CTS who do not have gross abnormalities in common conduction studies $(15,21)$. These patients can also profit from CTS surgery (5).

We have obtained very useful functional data on pressure distribution, not only in the carpal tunnel, but also distally in the palm and proximally in the distal antebrachial subfascial space. The graphs show that in all positions the highest pressure was recorded in the proximal part of carpal tunnel. In some patients, we not only measured higher pressure levels in the carpal tunnel, but also in the palm, especially during hand grip. This information was not only important during surgery, but also in the postoperative period to avoid excessive overloading of the hand and in changing working habits (21). With the aid of pressure measurement we are able to determine the distal functional border of the carpal ligament, which is an important piece of information for the surgeon, because the ligament should be transsected throughout its entire length (22). Incomplete transaction can be the cause CTS recurrence. After transsection, ICP should drop significantly. If not, more superficial layers of the palm should be dissected $(12,15)$. In our study this was done in 3 cases. This further dissection is likely to be the reason for better results in these patients.

\section{Conclusion}

Pressure measurement during CTS surgery provides new insight and provides the surgeon with valuable information such as the distal border of the carpal ligament, better control over ICP decompression and objectivization, enabling more repeatable results. These facts enabled us to complete decompression in 3 out of 31 patients, which without ICP measurement would probably not have been decompressed sufficiently. As far as postoperative EMG is concerned, improvement occurred in both groups, but a statistically significant difference between these two groups was not found i.e. ICP pressure measurement during CTS surgery did not have a significant effect on postoperative EMG improvement. Surgeons using endoscopy in CTS should keep in mind that conversion to the open approach is always an option (10) and before beginning with endo- 
scopic techniques, the surgeon should be familiar with the classic midpalmar approach.

\section{Acknowledgements}

This study was supported by IGA MZ CR 8404-3/2005.

\section{References}

1. Biyani A, Downes EM. An open twin incision technique of carpal tunnel decompression with reduced incidence of scar tenderness. J Hand Surg $[\mathrm{Br}$ 1993; 18,(3):331-4.

2. Concannon MJ, Brownfield ML, Puckett CL. The incidence of recurrence after endoscopic carpal tunnel release. Plast Reconstr Surg. 2000;105(5):1662-5.

3. Davies BW, Pennington GA, Fritz AM. Two-portal endoscopic carpal tunnel release: an outcome analysis of 333 hands. Ann Plast Surg. 1998;40(5):542-8.

4. Gelberman RH, Hergenroeder PT, Hargens AR, Lundborg GN, Akeson WH. The carpal tunnel syndrome. A study of carpal canal pressures. J Bone Joint Surg Am 1981;63(3):380-3.

5. Hamanaka I, Okutsu I, Shimizu K, et al. Evaluation of carpal canal pressure in carpal tunnel syndrome. J Hand Surg [Am] 1995;20(5):848-54.

6. Hashizume H, Nanba Y, Shigeyama Y, et al. Endoscopic carpal tunnel pressure measurement: a reliable technique for complete release. Acta Med Okayama 1997;51(2):105-10

7. Ikeda K, Osamura N, Tomita K. Segmental carpal canal pressure in patients with carpal tunnel syndrome. J Hand Surg [Am] 2006;31(6):925-9.

8. Jimenez DF, Gibbs SR, Clapper AT. Endoscopic treatment of carpal tunnel syndrome: a critical review. J Neurosurg 1998;88(5): 817-26.

9. Menon J. Endoscopic carpal tunnel release: a single-portal technique. Contemp Orthop1993;26(2):109-16.
10. Muller LP, Rudig L, Degreif J, Rommens PM. Endoscopic carpal tunnel release: results with special consideration to possible complications. Knee Surg Sports Traumatol Arthrosc 2000;8(3):166-72.

11. Nygaard OP, Trumpy JH, Mellgren SI. Recovery of sensory function after surgical decompression in carpal tunnel synrome. Acta Neurol Scand 1996;94:253-7.

12. Okutsu I, Hamanaka I, Tanabe T, et al. Complete endoscopic carpal canal decompression. Am J Orthop1996;25(5):365-8.

13. Okutsu I. Operative treatment for carpal tunnel syndrome. Brain Nerve 2007; Nov 59(11): 1239-45

14. Padua L, Padua R, Monaco M, et al. Natural history of carpal tunnel syndrome according to the neurophysiologic classification. Ital J Neurol Sci 1998;19: $357-61$.

15. Sekiya H, Sugimoto N, Kariya Y, Hoshino Y. Carpal tunnel pressure in patients with carpal tunnel syndrome due to long-term hemodialysis. Int Orthop. 2002;26(5):274-7.

16. Shinya K, Lanzetta M, Conolly WB. Risk and complications in endoscopic carpal tunnel release. J Hand Surg [Br] 1995;20(2):222-7.

17. Thoma A, Veltri K, Haines T, Duku E. A meta-analysis of randomized controlled trials comparing endoscopic and open carpal tunnel decompression. Plast Reconstr Surg. 2004 Oct;114(5):1137-46.

18. Uchiyama S, Toriumi $\mathrm{H}$, Nakagawa $\mathrm{H}$, et al. Postoperative nerve conduction changes after open and endoscopic carpal tunnel release. Clin Neurophysiol. 2002;113(1):64-70.

19. Watson BV, Brown WF, Doherty TJ. Frequency-dependent conduction block in carpal tunnel syndrome. Muscle Nerve 2006;33:619-26.

20. Weber RA, Sanders WE. Flexor carpi radialis approach for carpal tunnel release. J Hand Surg [Am]1997;22(1):120-6.

21. Werner R, Armstrong TJ, Bir MS. Intracarpal canal pressures: the role of finger, hand, wrist and forearm position. Clinical Biomechanice 1997;12(1): 44-51.

22. Yoshida A, Okutsu I, Hamanaka I. Is complete release of all volar carpal structures necessary for complete decompression in endosckopic carpal tunnel release? J Hand Surg Eur Vol. 2007 Oct;32(5): 537-42.

Submitted December 2008. Accepted April 2009.

\section{Corresponding author:}

MUDr. Martin Kanta, Ph.D., University Hospital Hradec Králové, Department of Neurosurgery, Sokolská 581, Hradec Králové, Czech Republic; e-mail: kantam@lfhk.cuni.cz 